\title{
Nöroprotektif Etkili Bir Flavonoid: Nobiletin
}

\author{
Gül Fatma YARIM ${ }^{1}$, Metin ÇENESiZ², Murat YARIM³ ${ }^{3}$ Sena ÇENESiZ ${ }^{1}$, Filiz KAZAK ${ }^{4 *}$ \\ ${ }^{1}$ Ondokuz Mayıs Üniversitesi, Veteriner Fakültesi, Biyokimya Anabilim Dalı, Samsun, Türkiye. \\ ${ }^{2}$ Ondokuz Mayıs Üniversitesi, Veteriner Fakültesi, Fizyoloji Anabilim Dalı, Samsun, Türkiye. \\ ${ }^{3}$ Ondokuz Mayıs Üniversitesi, Veteriner Fakültesi, Patoloji Anabilim Dalı, Samsun, Türkiye. \\ ${ }^{4}$ Mustafa Kemal Üniversitesi, Veteriner Fakültesi, Biyokimya Anabilim Dalı, Hatay, Türkiye.
}

Geliş Tarihi: 29.11.2016

Kabul Tarihi: 16.12.2016

Özet: Nörodejeneratif hastalıkların tedavisinde flavonoidlerin kullanımı yeni umutlar vaad etmektedir. Nobiletin, narenciye kabuklarında bulunan bir polimetoksi flavonoiddir. Nobiletinin nöroprotektif etkiye sahip olduğu pek çok in vivo ve in vitro araştırma ile ortaya konulmuştur. Nobiletin, öğrenme ve hafıza ile ilişkili sinyalizasyon kaskadlarını etkilemekte, enflamasyon mediyatörlerini modüle ederek nörodejenerasyonu hafifletmekte, dopamin salınımını artırarak motor ve bilişsel işlev bozukluğunu engellemekte, duygusal ve yenilikleri tanıma belleğini geliştirmektedir. Güncel çalışmalar, nobiletinin nörodejeneratif hastalıkların tedavisi için yeni bir ilaç olma potansiyeline sahip olduğunu desteklemektedir. Bu derlemede, nobiletinin nöroprotektif etkileri üzerinde durularak, literatürden elde edilen sonuçlar özetlenmiştir.

Anahtar Kelimeler: Flavonoid, Nobiletin, Nöroprotektif.

\section{A Flavonoid has Neuroprotective Effect: Nobiletin}

\begin{abstract}
The use of flavonoids promises new approach for the treatment of neurodegenerative diseases. Nobiletine is a polymethoxy flavonoid found in the citrus peel. The neuroprotective effect of nobiletin has been demonstrated in vivo and in vitro. Nobiletine affects the signaling cascades associated with learning and memory, alleviates neurodegeneration by modulating inflammatory mediators, inhibits motor and cognitive dysfunction by increasing dopamine release and enhances memory and recognition of emotions and innovations. Recent studies suggest that nobiletine has the potential to be a new drug for the treatment of neurodegenerative diseases. In this review, the neuroprotective effects of nobiletin was emphasized and the results obtained from the literature were summarized.

Keywords: Flavonoid, Nobiletin, Neuroprotective.
\end{abstract}

\section{Giriş}

Son yıllarda, nörodejeneratif hastalıkların tedavisi konusundaki bilimsel çalışmalar nöroprotektif etkili flavonoidlerin kullanımına yoğunlaşmaktadır. Flavonoidlerin, nörodejenerasyon modellerinde enflamasyon mediyatörlerini modüle ederek nörodejenerasyonu engellediği ya da hafiflettiği ileri sürülmektedir (Choi ve ark., 2014; Cui ve ark., 2014; Jung ve ark., 2014; Kim ve ark., 2012; Lee ve ark., 2014; Li ve ark., 2013; Schroeter ve ark., 2001; Vafeiadou ve ark., 2009; Vauzour ve ark., 2008). Çeşitli polifenollerin nörotrofik etkilerine aracılık eden ana sinyal yolakları Şekil 1'de sunulmuştur (Moosavi ve ark., 2015). Nörotrofik sinyalizasyon, Trk reseptörlerinin aktivasyonu ile Ras/MAPK, PI3K/Akt ve PL-C $\gamma$ yolakları aracilığıyla başlamaktadır. Polifenollerle Trk bağlanması, bu reseptörlerin otofosforilasyonunu ve aktivasyonunu sağlamaktadır. Reseptör fosforilasyonu, reseptörü MAPK, PI3K ve fosfolipaz $C_{\gamma}$ (PLC 1 1) yolaklarına bağlayan adaptör bağlama bölgelerini oluşturarak CREB proteininin fosforilasyonuna yol açmaktadır. CBP'ye bağlı fosforile CREB, CRE'ye bağlanarak hedef genlerin kopyalanmasına neden olmaktadır. Bu genler sağkalım, farklılaşma, büyüme, sinaptik plastisite ve uzun süreli bellek ile ilgilidir (Moosavi ve ark., 2015).

Nobiletin (3',4',5,6,7,8-hekzametoksiflavon), molekül ağırlığı $402.399 \mathrm{~g}$ olan ve narenciye kabuklarında bulunan bir polimetoksi flavonoiddir (Horowitz ve Gentilli, 1977; Li ve ark., 2006; Nogata ve ark., 2006). Nobiletinin kimyasal yapısı Şekil 2'de sunulmuştur (Nakajima ve ark., 2007). Oral yolla uygulanan nobiletin kan-beyin bariyerini geçerek beyin dokusuna ulaşmaktadır. Ratlarda nobiletinin oral yolla $50 \mathrm{mg} / \mathrm{kg}$ tek dozda uygulanmasından 1 saat sonra plazma ve beyindeki maksimum konsantrasyonlarının sırasıyla 1.78 ve $4.20 \mu \mathrm{g} / \mathrm{ml}$ ve eliminasyon yarı ömrünün ise sırasıyla 1.80 ve 11.42 saat olduğu belirlenmiştir (Singh ve ark., 2011). Nobiletin, biyolojik etkilerini N-metil-D-aspartat reseptörü aracılığı ile göstermektedir (Huang ve ark., 2016). Nobiletinin nöroprotektif etkiye sahip olduğu pek çok in vivo ve in vitro araştırma ile ortaya konulmuştur. Nobiletin, nörotrofik etkisini cAMP/PKA/MEK/Erk/MAP kinaz yolağını aktive ederek göstermektedir (Nagase ve ark., 2005; Nakajima ve ark., 2007). Nobiletin, NMDA reseptörü ile ERK aktivitesini ve CREB transkripsiyonel aktivitesini artırabilmektedir. Nobiletin, PKA sinyal 
yolağının modülasyonu ile DARPP-32 aktivitesini restore edebilmektedir. CREB transkripsiyonun upregülasyonunu sağlayan $\mathrm{Ca}^{+2} / \mathrm{CaMKII}$ sinyalizasyonu nobiletin tarafından uyarılmaktadır. Nobiletin, PI3K/Akt aktivitesini ve BDNF/TrkB sinyalizasyonunu ve PPARy ekspresyonunu upregüle etmektedir. Nobiletin, Nrf2 sinyalizasyonu aracılığıyla insülin duyarlılığını artırmaktadır (Şekil 3) (Huang ve ark., 2016). Nobiletin dışında mirisitrin, silibinin ve naringin gibi flavonoidlerin de substansiya nigradaki dopaminerjik nöronal hücre kaybının önlenmesinde olumlu etkileri olduğu gösterilmiştir (Jung ve ark., 2014; Leem ve ark., 2014; Kim ve ark., 2016). Naringenin, hesperidin ve bunların metabolitleri de dahil olmak üzere narenciyelerde bulunan flavonoidlerin kan beyin bariyerine nüfuz etme ve bu bariyeri geçme potansiyelleri bulunmaktadır (Youdim ve ark., 2004). Nobiletin, sadece kan beyin bariyerini geçmekle kalmamakta, aynı zamanda beyin dokusunda dolaşım ve periferik organlardan 3-4 kat daha yüksek konsantrasyonlarda bulunabilmektedir (Singh ve ark., 2011). Mandalina kabuğunda bulunan hesperidinin nobiletine göre miktarının fazla olmasına rağmen nobiletinin lipopolisakkarit ile indüklenen TNF- $\alpha$, IL-1 $\beta$ ve IL- 6 gibi proenflamatuar sitokinlerin salgılanmasını inhibe etmek için daha güçlü antienflamatuar kapasiteye sahip olduğu rapor edilmiştir (Ho ve Kuo, 2014). Ayrıca, tangeretin ile kıyaslandığında nobiletinin daha kuvvetli bir şekilde nitrik oksit üretimini engelleyici aktivite gösterdiği bildirilmiştir (Choi ve ark., 2007; Ho ve Kuo,2014).

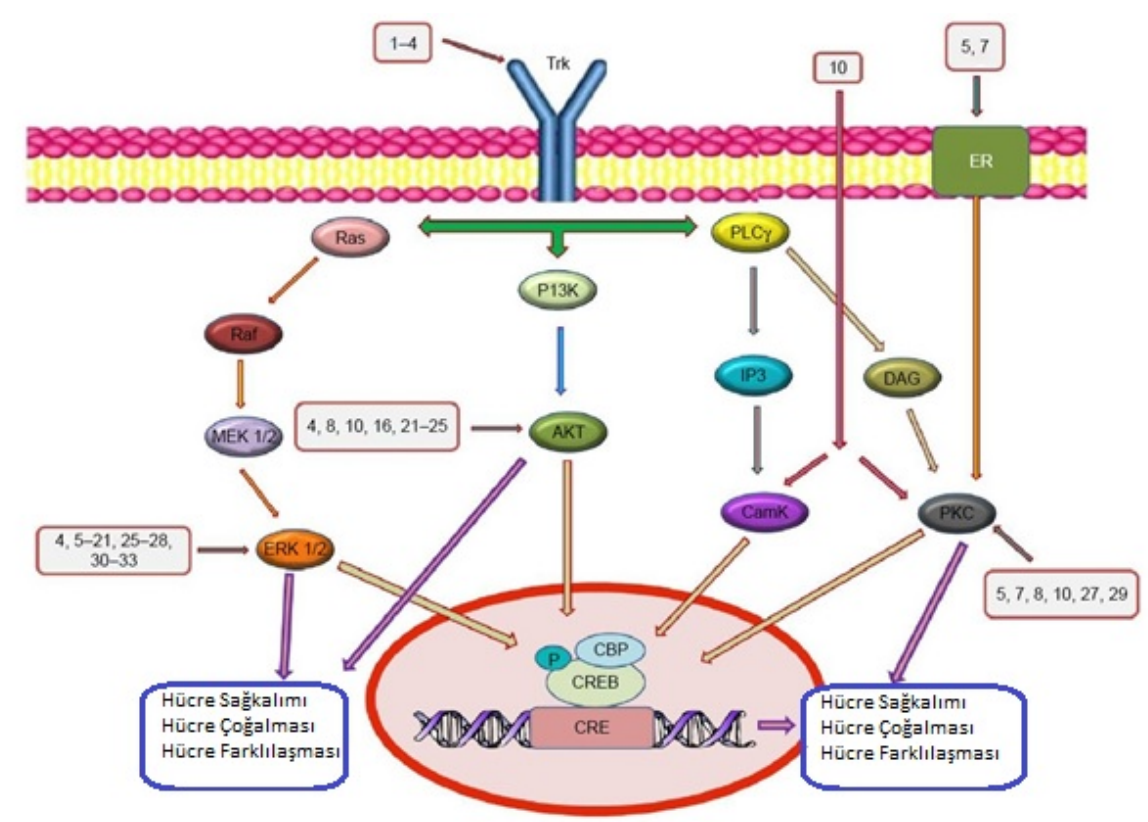

Şekil 1. Çeşitli polifenollerin nörotrofik etkilerine aracılık eden ana sinyal yolakları; 1: Epikateşin, 2: 7,8,3'-trihidroksiflavon, 3: diosmetin 4: 7,8-dihidroksifavon, 5: daidzein, 6: resveratrol, 7: hesperetin, 8: kurkuminoidler, 9: kafeik asit fenetil ester, 10: ferulik asit, 11: baikalein, 12: apigenin, 13: honokiol, 14: nobiletin, 15: pinokembrin, 16: astilbin, 17: artepillin C, 18: 3,5,6,7,8,3',4'-heptametoksiflavon, 19: 4'-O- $\beta$-D-glikopiranozil-30,4- dimetoksikalkon, 20: fustin, 21: puerarin, 22: skutellarin, 23: oroksilin A, 24: metil 3,4-dihidroksibenzoat, 25: karnosik asit, 26: rosmarinik asit, 27: luteolin, 28: aurapten, 29: epigallokateşin 3 gallat, 30: icaritin, 31: likiritin, 32: fisetin, 33: rutin, CaMK, Ca+2-kalmodulin kinaz; CREB, siklik adenozin monofosfat yanıt elementini bağlayıcı protein; CBP, CREB-bağlayıcı protein; DAG, diasilgliserol; ER, östrojen reseptörü; ERK, hücre dışı sinyalle düzenlenen kinaz; IP3, inositol trisfosfat; MAPK, mitojenle aktiflenen protein kinaz; MEK, Mitojenle aktive edilen protein kinaz kinazı; PI3K, fosfatidilinositol-3-kinaz; PKC, protein kinaz C; PLC , fosfolipaz C-gama; Trk, tropomiyozin reseptör kinaz (Moosavi ve ark., 2015).<smiles>COc1ccc(-c2cc(=O)c3c(OC)c(OC)c(OC)c(OC)c3o2)cc1OC</smiles>

Şekil 2. Nobiletinin kimyasal yapısı (Nakajima ve ark., 2007). 


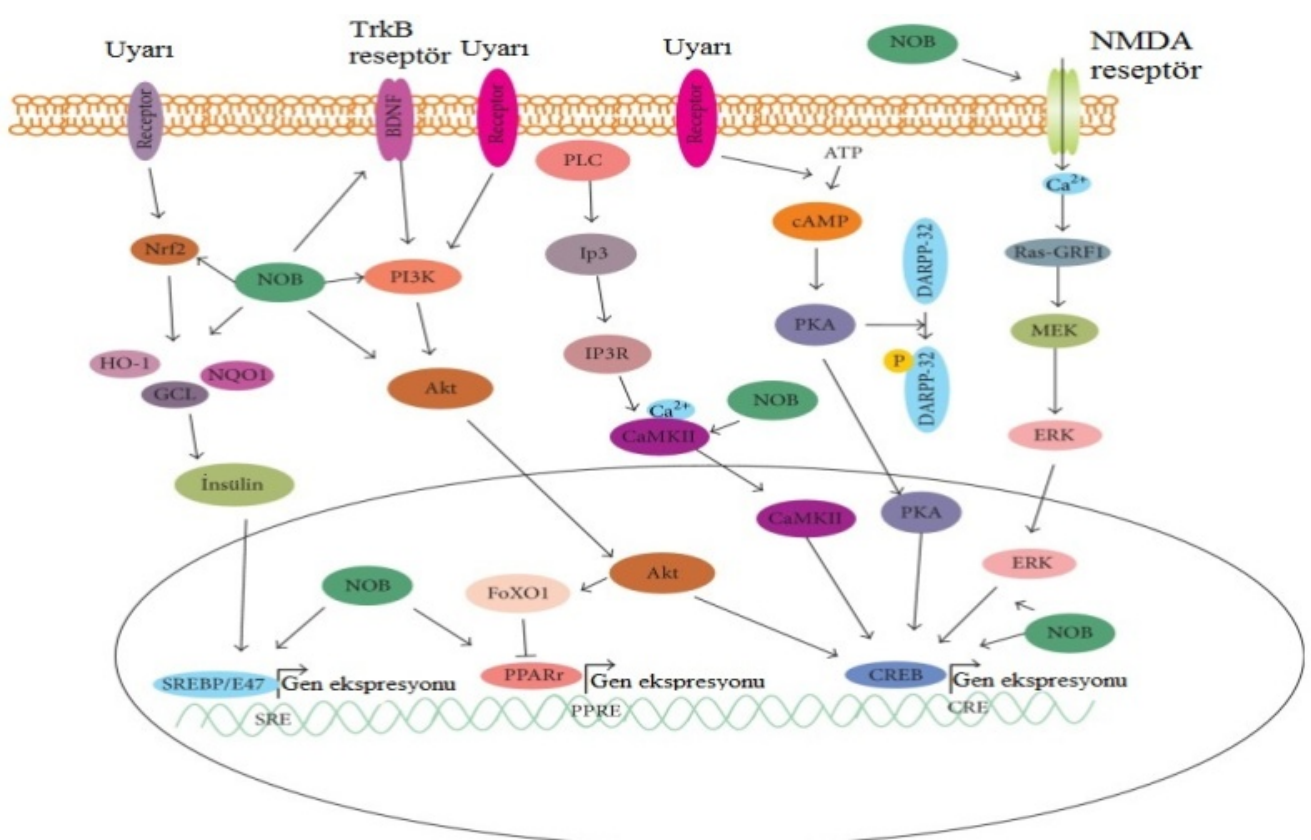

Şekil 3. Nobiletinin hücrelerdeki sinyalizasyon kaskadları (Huang ve ark., 2016).

Nobiletinin nöroprotektif etkisini gösteren in vivo çalışmalar:

Nobiletinin nöroprotektif etki gösterdiği pek çok in vivo araştırma ile kanıtlanmıştır. Nobiletinin farelerde N-metil-D-aspartat reseptör antagonizmi ile bağlantılı öğrenme yeteneklerinin azalmasını hücre dışı sinyal ile düzenlenen kinaz sinyal aktivasyonu ile hafiflettiği ortaya konulmuş ve bilişsel bozukluklarla karakterize nörolojik bozukluklar için terapötik ilaç geliştirme konusunda yeni bir yaklaşım olabileceği ifade edilmiştir (Nakajima ve ark., 2007). Nobiletinin yaşlı ratlarda izofluranla indüklenen bilişsel bozukluğu Akt, Bax, p-CREB ve BDNF'nin modülasyonuyla antioksidan, antienflamatuar ve antiapoptotik etkiler göstererek iyileştirdiği ortaya konulmuştur (Bi ve ark., 2016). Kuprizonla indüklenen demiyelinasyon modelinde nobiletinin oligodendroglial hücreler üzerindeki etkisinin incelendiği bir çalışmada, C57BL/6 farelere 3 hafta boyunca haftada $2 \mathrm{kez}$ periton içi $50 \mathrm{mg} / \mathrm{kg}$ nobiletin uygulamasının olgun oligodendrositlerin belirteci olan proteolipit proteine karşı immunoreaktiviteyi artırdığı ve nobiletin uygulamasının demiyelinasyonla seyreden multipl skleroz gibi hastalığı olan bireyler için uygun olabileceği ifade edilmiştir (Nakajima ve ark., 2015b).

Nobiletinin farelerde duygusal ve yenilikleri tanıma belleğini geliştirdiği rapor edilmiştir (Kang ve ark., 2016). Alzheimer hastalığı rat modelinde nobiletin uygulamasının beta amiloid engelli cAMP yanıt elemanı bağlayan proteinin (CREB) fosforilasyonunu sağlayarak hafıza kaybını engellediği rapor edilmiştir (Matsuzaki ve ark., 2006).
Alzheimer modeli oluşturulmuş transgenik farelerde 4 ay boyunca periton içi nobiletin uygulamasının hipokampustaki beta amiloid peptid yükünü ve plaklarını azalttığı belirlenmiştir (Onozuka ve ark., 2008). Yamamoto ve ark. (2009), nobiletinin beyin iskemisinin neden olduğu öğrenme ve hafıza bozukluğunu CaMKII ve CREB fosforilasyonunu uyararak giderdiğini ve nobiletinin Alzheimer tedavisi için yeni ve öncü bir bileşik olabileceğini ifade etmişlerdir. Yaşa bağlı bilişsel bozulmanın yanı sıra Alzheimer hastalığı ile ilgili nöropatolojinin önlenmesinde, beta amiloid oligomer düzeylerinin azaltılmasında, tau hiperfosforilasyonu ve oksidatif stresin baskılanmasında nobiletinin yararlı etkileri bildirilmiştir (Nakajima ve ark., 2013; 2015a).

Serebral iskemi rat modelinde periton içi nobiletin uygulamasının Nrf2 ve HO-1 ekspresyonlarını artırarak ve NF-kB ekspresyonunu azaltarak nörolojik bozukluk ve beyin ödemini hafiflettiği rapor edilmiştir (Zhang ve ark., 2016). Nobiletinin ratlarda serebral iskemi-reperfüzyon hasarına bağlı gelişen infarkt hacmini ve beyin ödemini önemli ölçüde azalttığı, motor fonksiyon bozukluklarını iyileştirdiği bildirilmiştir (Yasuda ve ark., 2014). Serebral orta arter oklüzyonu oluşturulan ratlarda, nobiletinin p-Akt, p-CREB, $B D N F$ ve $B c l-2$ yolaklarını aktive ederek ve kan-beyin bariyeri geçirgenliğini düzelterek serebral iskemiye karşı beyini koruduğu rapor edilmiştir (Zhang ve ark., 2013). Yabuki ve ark. (2014), Parkinson modeli oluşturdukları farelerde nobiletinin beyinde dopamin salınımını artırarak, motor ve bilişsel işlev bozukluğunu engellediğini ortaya koymuşlardır. Nobiletinin ratlarda oluşturulan deneysel Parkinson 
hastalığı modelinde, substansiya nigrada bulunan dopaminerjik nöronları, mikrogliyal aktivasyonu engelleyerek ve gliyal hücre kaynaklı nörotrofik faktör ekspresyonunu artırarak koruduğu anlaşılmıştır (Jeong ve ark., 2015).

\section{Nobiletinin nöroprotektif etkisini gösteren in vitro çalışmalar:}

Mikrogliya hücre kültüründe, hipokampal nöron kültüründe ve rat feokromasitoma hücre hattında gerçekleştirilen çalışmalar, nobiletinin nöroprotektif etkiye sahip olduğunu ortaya koymaktadır. Lipopolisakkaritle uyarılmış BV-2 mikrogliya hücre kültürü modelinde nobiletinin, ERK, JNK, p38 MAPKs ve NF-kB sinyal yolaklarını inhibe ederek aşırı mikrogliyal aktivasyonu baskıladığı bildirilmiştir (Cui ve ark., 2010). Nobiletinin in vitro LPS ile indüklenen proenflamatuar NO, TNF- $\alpha$, IL-1 $\beta$ ve IL-6 sekresyonunu azalttığı rapor edilmiştir (Ho ve Kuo, 2014). Nobiletinden zengin mandalina kabuğu ekstraktının hipokampal nöron kültüründe öğrenme ve hafıza ile ilişkili CAMP/PKA/ERK/CREB sinyalizasyonunu uyardığı rapor edilmiştir (Kawahata ve ark., 2013). Hipokampal nöron kültüründe nobiletin uygulamasının alfa-amino-3-hidroksi-5-metil-4izoksazol propiyonik asit resöptörünün protein kinaz A-aracılı fosforilasyonunu artırarak nörotrofik etki gösterdiği ileri sürülmüştür (Matsuzaki ve ark., 2008).

Oligodendrositlerin büyüme ve sağkalımında fosfatidilinositol 3-kinaz ve mitojen-aktive eden protein kinaz yolaklarının aktivasyonu rol oynamaktadır (Hiraiwa ve ark., 1997; Vemuri ve McMorris, 1996). Nobiletinin cAMP / PKA / MEK / Erk / MAP kinaz yolağını aktive ederek nörotrofik etki gösterdiği belirlenmiştir (Nagase ve ark., 2005). Cho ve ark. (2015), nobiletinin HT22 nöronlarını hidrojen peroksit kaynaklı hücre ölümüne karşı mitojen-aktive protein kinazlar ve apoptotik yolaklar aracılığıyla koruduğunu bildirmişlerdir. Hidrojen peroksite maruz bırakılan PC12 hücre hattında nobiletin uygulamasının hücre ölümünü ve kaspaz-3 aktivitesini inhibe ettiği, membran hasarını önlediği, ROS oluşumunu azalttığı ve mitokondriyal membran potansiyelinin azalmasını hafiflettiği anlaşılmıştır (Lu ve ark., 2010). Araştırıcılar, hidrojen peroksitle indüklenen sitotoksisiteye karşı nobiletinin nöroprotektif etkili olduğunu ve diyetle alınacak bu antioksidanın nörodejeneratif hastalıklar için potansiyel aday olduğunu ileri sürmüşlerdir.

\section{Sonuç}

Nöroprotektif etkili flavonoidler, nörodejeneratif hastalıkların proflaksisinde ve tedavisinde başarı sağlamaktadır. Nöroprotektif etkili bir flavonoid olan nobiletin, bilişsel aktiviteyi artırıcı etkisiyle ön plana çıkmaktadır. Nobiletin, nörodejenerasyon modellerinde enflamasyon mediyatörlerini modüle ederek nörodejenerasyonu engellemek ya da hafifletmek amaçlı kullanım alanı bulmaktadır. Bilimsel çalışmalar, doğal bir flavonoid olan nobiletinin nörodejeneratif hastalıkların tedavisi için yeni bir ilaç olma potansiyeline sahip olduğunu göstermektedir.

\section{Kaynaklar}

Bi J, Zhang H, Lu J, Lei W, 2016: Nobiletin ameliorates isoflurane-induced cognitive impairment via antioxidant, anti-inflammatory and anti-apoptotic effects in aging rats. Mol Med Rep, 14, 6, 5408-5414.

Cho HW, Jung SY, Lee GH, Cho JH, Choi IY, 2015: Neuroprotective effect of Citrus unshiu immature peel and nobiletin inhibiting hydrogen peroxideinduced oxidative stress in HT22 murine hippocampal neuronal cells. Pharmacogn Mag, 11, Suppl 2, 284-289.

Choi SY, Ko HC, Ko SY, Hwang JH, Park JG, Kang SH, Han SH, Yun SH, Kim SJ, 2007: Correlation between flavonoid content and the NO production inhibitory activity of peel extracts from various citrus fruits. Biol Pharm Bull, 30, 4, 772-778.

Choi SM, Kim BC, Cho YH, Choi KH, Chang J, Park MS, Kim MK, Cho KH, Kim JK, 2014: Effects of flavonoid compounds on $\beta$-amyloid-peptide-induced neuronal death in cultured mouse cortical neurons. Chonnam Med J, 50, 2, 45-51.

Cui Y, Wu J, Jung SC, Park DB, Maeng YH, Hong JY, Kim SJ, Lee SR, Kim SJ, Kim SJ, Eun SY, 2010: Antineuroinflammatory activity of nobiletin on suppression of microglial activation. Biol Pharm Bull, 33, 11, 1814-1821.

Cui QJ, Wang LY, Wei ZX, Qu WS, 2014: Continual naringin treatment benefits the recovery of traumatic brain injury in rats through reducing oxidative and inflammatory alterations. Neurochem Res, 39, 7, 1254-1262.

Hiraiwa M, Taylor EM, Campana WM, Darin SJ, O'Brien JS, 1997: Cell death prevention, mitogen-activated protein kinase stimulation, and increased sulfatide concentrations in Schwann cells and oligodendrocytes by prosaposin and prosaptides. Proc Natl Acad Sci USA, 94, 9, 4778-4781.

Ho SC, Kuo CT, 2014: Hesperidin, nobiletin, and tangeretin are collectively responsible for the antineuroinflammatory capacity of tangerine peel (Citri reticulatae pericarpium). Food Chem Toxicol, 71, 176-182. 
Horowitz RM, Gentilli B, 1977: Flavonoid constituents of citrus. In: Nagy S, Shaw PE, Veldhuis MK, editors. CT: Avi Publishing Company Inc., Citrus Science and Technology, Westport.

Huang H, Li L, Shi W, Liu H, Yang J, Yuan X, Wu L, 2016: The Multifunctional Effects of Nobiletin and Its Metabolites In Vivo and In Vitro. Evid Based Complement Alternat Med, 2016, 2918796.

Jeong KH, Jeon MT, Kim HD, Jung UJ, Jang MC, Chu JW, Yang SJ, Choi IY, Choi MS, Kim SR, 2015: Nobiletin protects dopaminergic neurons in the 1-methyl-4phenylpyridinium-treated rat model of Parkinson's disease. J Med Food, 18, 4, 409-414.

Jung UJ, Jeon MT, Choi MS, Kim SR, 2014: Silibinin attenuates $\mathrm{MPP}^{+}$-induced neurotoxicity in the substantia nigra in vivo. J Med Food, 17, 5, 599-605.

Kang J, Shin JW, Kim YR, Swanberg KM, Kim Y, Bae JR, Kim YK, Lee J, Kim SY, Sohn NW, Maeng S, 2016: Nobiletin improves emotional and novelty recognition memory but not spatial referential memory. J Nat Med, 71, 1, 181-189.

Kawahata I, Yoshida M, Sun W, Nakajima A, Lai Y, Osaka N, Matsuzaki K, Yokosuka A, Mimaki Y, Naganuma A, Tomioka Y, Yamakuni T, 2013: Potent activity of nobiletin-rich Citrus reticulata peel extract to facilitate CAMP/PKA/ERK/CREB signaling associated with learning and memory in cultured hippocampal neurons: identification of the substances responsible for the pharmacological action. J Neural Transm (Vienna), 120, 10, 1397-1409.

Kim HG, Ju MS, Ha SK, Lee H, Lee H, Kim SY, Oh MS, 2012: Acacetin protects dopaminergic cells against 1methyl-4-phenyl-1,2,3,6-tetrahydropyridine-induced neuroinflammation in vitro and in vivo. Biol Pharm Bull, 35, 8, 1287-1294.

Kim HD, Jeong KH, Jung UJ, Kim SR, 2016: Myricitrin ameliorates 6-hydroxydopamine-induced dopaminergic neuronal loss in the substantia nigra of mouse brain. J Med Food, 19, 4, 374-382.

Lee E, Park HR, Ji ST, Lee Y, Lee J, 2014: Baicalein attenuates astroglial activation in the 1-methyl-4phenyl-1,2,3,4-tetrahydropyridine-induced Parkinson's disease model by downregulating the activations of nuclear factor-KB, ERK, and JNK. J Neurosci Res, 92, 1, 130-139.

Leem E, Nam JH, Jeon MT, Shin WH, Won SY, Park SJ, Choi MS, Jin BK, Jung UJ, Kim SR, 2014: Naringin protects the nigrostriatal dopaminergic projection through induction of GDNF in a neurotoxin model of Parkinson's disease. J Nutr Biochem, 25, 7, 801-806.

Li S, Yu H, Ho CT, 2006: Nobiletin: efficient and large quantity isolation from orange peel extract. Biomed Chromatogr, 20, 1, 133-138.

Li R, Liang T, Xu L, Zheng N, Zhang K, Duan X, 2013: Puerarin attenuates neuronal degeneration in the substantia nigra of 6-OHDA-lesioned rats through regulating BDNF expression and activating the Nrf2/ARE signaling pathway. Brain Res. 1523, 1-9.

Lu YH, Su MY, Huang HY, Lin-Li, Yuan CG, 2010: Protective effects of the citrus flavanones to PC12 cells against cytotoxicity induced by hydrogen peroxide. Neurosci Lett, 484, 1, 6-11.
Matsuzaki K, Yamakuni T, Hashimoto $M$, Haque AM, Shido O, Mimaki Y, Sashida Y, Ohizumi Y, 2006: Nobiletin restoring beta-amyloid-impaired CREB phosphorylation rescues memory deterioration in Alzheimer's disease model rats. Neurosci Lett, 400, 3, 230-234.

Matsuzaki K, Miyazaki K, Sakai S, Yawo H, Nakata N, Moriguchi S, Fukunaga K, Yokosuka A, Sashida Y, Mimaki Y, Yamakuni T, Ohizumi Y, 2008: Nobiletin, a citrus flavonoid with neurotrophic action, augments protein kinase A-mediated phosphorylation of the AMPA receptor subunit, GluR1, and the postsynaptic receptor response to glutamate in murine hippocampus. Eur J Pharmacol, 578, 194-200.

Moosavi F, Hosseini R, Saso L, Firuzi O, 2015: Modulation of neurotrophic signaling pathways by polyphenols. Drug Des Devel Ther, 10, 23-42.

Nagase H, Yamakuni T, Matsuzaki K, Maruyama $Y$, Kasahara J, Hinohara $Y$, Kondo S, Mimaki $Y$, Sashida Y, Tank AW, Fukunaga K, Ohizumi Y, 2005: Mechanism of neurotrophic action of nobiletin in PC12D cells. Biochemistry, 44, 42, 13683-13691.

Nakajima A, Yamakuni T, Matsuzaki K, Nakata N, Onozuka H, Yokosuka A, Sashida Y, Mimaki Y, Ohizumi Y, 2007: Nobiletin, a citrus flavonoid, reverses learning impairment associated with $\mathrm{N}$-methyl-D-aspartate receptor antagonism by activation of extracellular signal-regulated kinase signaling. J Pharmacol Exp Ther, 321, 2, 784-790.

Nakajima A, Aoyama Y, Nguyen TT, Shin EJ, Kim HC, Yamada S, Nakai T, Nagai T, Yokosuka A, Mimaki Y, Ohizumi Y, Yamada K, 2013: Nobiletin, a citrus flavonoid, ameliorates cognitive impairment, oxidative burden, and hyperphosphorylation of tau in senescence-accelerated mouse. Behav Brain Res, 250, 351-360.

Nakajima A, Aoyama Y, Shin EJ, Nam Y, Kim HC, Nagai T, Yokosuka A, Mimaki Y, Yokoi T, Ohizumi Y, Yamada K, 2015a: Nobiletin, a citrus flavonoid, improves cognitive impairment and reduces soluble $A \beta$ levels in a triple transgenic mouse model of Alzheimer's disease (3XTg-AD). Behav Brain Res, 289, 69-77.

Nakajima $M$, Shimizu R, Furuta K, Sugino $M$, Watanabe $T$, Aoki R, Okuyama S, Furukawa Y, 2015b: Nobiletin induces oligodendrocyte lineage precursor cells in a cuprizone-administered demyelination animal model. J Mult Scler (Foster City), 2 4, 1-6.

Nogata Y, Sakamoto K, Shiratsuchi H, Ishii T, Yano M, Ohta $\mathrm{H}$, 2006: Flavonoid composition of fruit tissues of citrus species. Biosci Biotechnol Biochem, 70, 1, 178192.

Onozuka H, Nakajima A, Matsuzaki K, Shin RW, Ogino K, Saigusa D, Tetsu N, Yokosuka A, Sashida Y, Mimaki Y, Yamakuni T, Ohizumi Y, 2008: Nobiletin, a citrus flavonoid, improves memory impairment and Abeta pathology in a transgenic mouse model of Alzheimer's disease. J Pharmacol Exp Ther, 326, 3, 739-744.

Schroeter H, Spencer JP, Rice-Evans C, Williams RJ, 2001: Flavonoids protect neurons from oxidized lowdensity-lipoprotein-induced apoptosis involving cJun N-terminal kinase (JNK), c-Jun and caspase-3. Biochem J, 358 (Pt 3), 547-557. 
Singh SP, Wahajuddin, Tewari D, Patel K, Jain GK, 2011: Permeability determination and pharmacokinetic study of nobiletin in rat plasma and brain by validated high-performance liquid chromatography method. Fitoterapia, 82, 8, 1206-1214.

Vafeiadou K, Vauzour D, Lee HY, Rodriguez-Mateos A, Williams RJ, Spencer JP, 2009: The citrus flavanone naringenin inhibits inflammatory signalling in glial cells and protects against neuroinflammatory injury. Arch Biochem Biophys, 484, 1, 100-109.

Vauzour D, Vafeiadou K, Rodriguez-Mateos A, Rendeiro C, Spencer JP, 2008: The neuroprotective potential of flavonoids: a multiplicity of effects. Genes Nutr, 3 (34), 115-126.

Vemuri GS, McMorris FA, 1996: Oligodendrocytes and their precursors require phosphatidylinositol 3kinase signaling for survival. Development, 122, 8, 2529-2537.

Yabuki Y, Ohizumi Y, Yokosuka A, Mimaki Y, Fukunaga K, 2014: Nobiletin treatment improves motor and cognitive deficits seen in MPTP-induced Parkinson model mice. Neuroscience, 259, 126-141.

Yamamoto Y, Shioda N, Han F, Moriguchi S, Nakajima A, Yokosuka A, Mimaki Y, Sashida Y, Yamakuni T, Ohizumi Y, Fukunaga K, 2009: Nobiletin improves brain ischemia-induced learning and memory deficits through stimulation of CaMKII and CREB phosphorylation. Brain Res, 1295, 218-229.
Yasuda N, Ishii T, Oyama D, Fukuta T, Agato Y, Sato A, Shimizu K, Asai T, Asakawa T, Kan T, Yamada S, Ohizumi Y, Oku N, 2014: Neuroprotective effect of nobiletin on cerebral ischemia-reperfusion injury in transient middle cerebral artery-occluded rats. Brain Res, 1559, 46-54.

Youdim KA, Qaiser MZ, Begley DJ, Rice-Evans CA, Abbott NJ, 2004: Flavonoid permeability across an in situ model of the blood-brain barrier. Free Radic Biol Med, 36, 5, 592-604.

Zhang L, Zhao H, Zhang X, Chen L, Zhao X, Bai X, Zhang J, 2013: Nobiletin protects against cerebral ischemia via activating the p-Akt, p-CREB, BDNF and $\mathrm{Bcl}-2$ pathway and ameliorating BBB permeability in rat. Brain Res Bull, 96, 45-53.

Zhang L, Zhang X, Zhang C, Bai X, Zhang J, Zhao X, Chen L, Wang L, Zhu C, Cui L, Chen R, Zhao T, Zhao Y, 2016: Nobiletin promotes antioxidant and antiinflammatory responses and elicits protection against ischemic stroke in vivo. Brain Res, 1636, 130141.

\section{*Yazışma Adresi: Filiz KAZAK}

Mustafa Kemal Üniversitesi, Veteriner Fakültesi, Biyokimya Anabilim Dalı, Hatay, Türkiye. e-mail: filizkazak@mku.edu.tr 